\title{
Cultural Diversity: Implications For Workplace Management
}

\author{
Donatus I. Amaram, (E-mail: damaram@vsu.edu), Virginia State University
}

\begin{abstract}
The acceptance and management of cultural diversity have been promoted and touted as a positive tool in social and organizational engineering aimed at solving and preventing group dynamics problems in both business organizations and society as well. Positive attributes of cultural integration in business organizations have received fair and significant attention in the past two decades. What have not been sufficiently presented are the challenges and pitfalls inherent in the management of culturally diverse work groups. For the practicing manager, there is a need to know when and where mono- and multi-cultural arrangements may be preferred. This paper reviews relevant research findings that can be used for building effective paradigms in the management of cultural diversity in the workplace.
\end{abstract}

\section{INTRODUCTION}

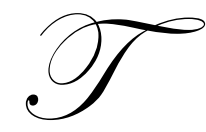

he last two decades have seen significant efforts on the part of scholars and policy makers to embark on initiatives to acknowledge, accept, and value cultural differences among ethnic groups in place of the traditional melting pot approach whose objectives have been to assimilate minorities into the mainstream at the expense of their cultural identities. This changing accent on accepting differences and diversity has led to a new and emerging school of thought on how to manage people and organizations for effective performance in a globally competitive business environment. This requires crafting management concepts and application techniques to deal with the challenges and opportunities posed by an increasingly diverse culture. These challenges and opportunities include cultural influences on job satisfaction, levels of inter-group biases and prejudices, degrees of cooperativeness and overall individual and group performance. This paper reviews the "culture literature" and attempts to synthesize research findings on the effects of cultural diversity on issues and attributes relative to comparative work behavior of various ethnic groups.

\section{CHANGING PERSPECTIVES OF CULTURAL DIVERSITY}

Efforts to protect and improve the rights of minorities over the past two decades have led to a rethinking of the propriety of the "melting pot" mentality and the exploration of new perspectives on the management of cultural diversity in the workplace. Cultural diversity has been defined as "the representation, in one social system, of people with distinctly different group affiliations of cultural significance" (Cox, 1993). The traditional approach to handling multiculturalism in complex organizations has been to expect members of the minority culture to adapt to the cultural requirements of the majority group. What forces have triggered the subtle but perceptible shift away from assimilation and towards diversity? Several organizational dynamics contribute to the growth of the diversity perspective. First, a quest for social justice, though a goal of the assimilation concept, has been largely elusive under it. Moral, ethical and social responsibilities toward minority members of society and of business organizations in particular have provided the impetus for a search for new and better paradigms to improve the lot of racio-ethnic and gender minorities. Second, legal obligations arising from civil rights laws and the attendant affirmative action programs have made it necessary for organizations to find alternative ways to eliminate racial and gender discrimination in education and employment (Ramakrishnan and Balgopal, 1995). Third, the limitations of affirmative action which have led to calls for new proposals to replace it, (Gottfredson, 1992, p.279; Thomas, 1990, p. 107) and the strategic imperatives imposed on American businesses for competitive advantage in the global marketplace, have created more pressures to acknowledge and deal with cultural diversity in a way that recognizes 
and works with differences in cultures without denigrating or submerging some under others. Globalization, with its multicultural implications, has become an indispensable factor in strategic competitiveness. IBM, Exxon, Coca Cola, and Dow Chemical, for example, derive, at least, half of their revenues from other countries. For the first time since World War I, immigrants make up the largest share of recent growth in the population and the labor force. Experts predict that business leaders who ignore these demographic trends will find themselves at a competitive disadvantage (Copeland, 1988b; Nkomo, 1992). Hitherto, cultural differences were perceived only in terms of ethnic and nationality constructs. Now, cultural considerations include race, gender, sexual orientation, age, disability etc. These subgroups possess different work attitudes, perceptions, values and norms which, in turn, affect individual and group performances. The conclusions of Workforce 2000: Work and Workers for the $21^{\text {st }}$ Century_(Johnston, 1987), highlight the importance and impact of changing workforce demographics and diversity in organizations. Differences in cultural composition of the workplace lead to tensions and conflicts over cultural issues, particularly from minority workers who are more likely to feel oppressed by the differences. For business organizations, these changes offer both opportunities and challenges.

\section{DIVERSITY AND ORGANIZATIONAL SUCCESS FACTORS}

The observed effects of cultural diversity on organizational behavior have been multi-variant and seem to depend on how different groups are combined and permuted in the workplace. Rubaii-Barrett and Beck (1993) examined the similarities and differences in work climate perceptions and levels of job satisfaction among AngloAmerican and Mexican-American local government employees and reported that Mexican-American employees felt higher levels of satisfaction with personnel procedures than did Anglo-American employees. Because the MexicanAmericans constituted the majority of the two groups, it was inferred that cultural differences rather than numerical minority status were responsible for the observed differences in work attitudes on the part of the Anglo employees.

One area of cultural differences which has been studied sufficiently over time is the contrast between individualism and collectivism and the impact on behavior of people from nations in which various ethnic groups of the United States have historical roots (Triandis, McCusker, and Hui, 1990). Asians, Hispanics and Blacks have roots in nations with collectivist cultures, while Caucasians have roots in the European tradition of individualism (Hofstede, 1980, Inkeles, 1983). This fact has been used to predict the effectiveness of management practices relative to team work and group cooperativeness. Earley (1993) examined 163 managers from China, Israel and the United States to assess the effects of individualistic/collectivistic cultural beliefs on performance and found that the performance of individualists (those from the U.S.) was lower when working in a group than when working alone, while the performance of collectivists (those from China and Israel) was lower when working alone than when working in a group. Perkins (1993) corroborated these findings, and went further to assess attitudes and preferences relative to work- group structures and found that those from cultures that view relationships in terms of hierarchy or pecking order have a preference for highly structured teams while those from individualistic cultures felt more comfortable with voluntary and informal teams.

\section{IMPACT ON COOPERATIVE AND COMPETITIVE BEHAVIOR}

Team work and competitive assignments are legitimate and recurrent tools in the strategic activities of many business organizations. Knowledge of how cultural diversity affects the effectiveness of these work arrangements is significant for managerial decision making. Cox (1991) examined the effects on group tasks of ethnic group differences between Asians, Blacks, Hispanics and Caucasians and concluded that those from collectivist cultural traditions exhibit more cooperative behavior than those from individualistic cultural origins. In addition to inter-cultural differences, some intra-cultural attributes have been found to exert significant behavioral tendencies that affect interpersonal interactions. Physical observable differences or phenotypes, for instance, affect the level of acceptability and assimilation of organization members even within their own cultural groups. It is not surprising that persons of phenotypes different from the majority group tend to have less favorable work experiences and career outcomes (such as satisfaction, compensation, promotion etc) than persons from the majority phenotype. What is surprising is that within the same group, differences in physical attributes do affect these issues with equal force. 


\section{CAREER IMPLICATIONS}

Within phenotypes there is an inverse correlation between the amount of physical distinctiveness from the majority group and career outcomes. All things being equal, it has been found that women with long hair and ultra feminine dress fare less well than women with shorter hairstyles and more masculine dress; and non-Whites of light skin color fare better than non-Whites of darker skin color, leading one researcher to conclude that "skin color is probably the most important single index for uncritical human evaluation" (Lincoln, 1967, p. 527). There is evidence that strong identification with the majority culture enhances one's career progression. Furthermore, it has been noted that organizational members with mono-cultural minority-group identity have more negative career experiences than those with other identity affiliations. Biculturals are at a disadvantage compared to mono-majority members but experience better career outcomes than those of mono-minority members (Bell, 1990).

Career outcomes tend to be more positive when phenotype and culture are congruent than when they are dissimilar (Cox, 1993, p. 62). Thus, it's instructive for managers to note that an organization's cultural mix affects the ability of out-group members to perform within the organization. Some derivatives of cultural diversity that negatively affect minority culture members include prejudice, discrimination and stereotyping. Prejudice here is understood as a prejudgment of someone on the basis of some characteristics which may include cultural idiosyncrasies, while discrimination speaks to behavioral biases toward a person based on his/her group identity. Research suggests that minority group size also affects the level of discrimination.

Majority group members tend to increase levels of discrimination against minorities when the latter's percentage of representation is low (Blau, 1977). Stereotyping also presents an obstacle to minority group members of an organization. Stereotyping is a form of prejudgment by which we attribute to an individual the supposed attributes of the group from which he comes. Research findings suggest that stereotyping can have significant negative effects on both individual careers and overall organizational performance. For example, stereotyping has been found to affect hiring, promotion and performance evaluation decisions of overweight people, older employees and applicants, as well as people with disabilities (Everett, 1990)).

\section{TRENDS IN PREJUDICE/DISCRIMINATION}

Are the influences of culturally-associated prejudice and discrimination declining or increasing over time? There is evidence for both sides of the argument. Firebaugh and Davis (1988) concluded that prejudice declined significantly in a study of African Americans from 1972 to 1984. An American Management Association study concurred and concluded that the increases in minority representation in managerial positions were largely attributable to changes in attitudinal dispositions toward minorities rather than government-mandated affirmative action programs (Romano, 1995, p.6). On the other hand, several research findings have suggested that significant prejudice toward cultural minorities persists (Cockrel, 1989). In a study of 200 Black professionals, Morrison (1992) found that prejudice in its various subtle forms pervaded organizational decision making and caused widespread disappointment, frustration and anger among these professionals struggling to advance in a culturally hostile atmosphere. Organizational members from minority subgroups also face obstacles from ethnocentrism within an organization's culture. Ethnocentrism is the inclination for majority-group members to view themselves as the center of the universe, to interpret minority out-group members from the perspective of the majority group, and to evaluate beliefs, behaviors, and values of the majority group more positively than those of the minority group members (Shimp \& Sharma, 1987). The overall conclusion is that prejudice, discrimination and stereotyping are widely practiced in organizations and negatively impact the careers of minority group members (Lester \& Caudill, 1987; Schweltzer and Deely, 1982). As the workforce grows more diverse, tensions over cultural issues are bound to exacerbate. The attendant cultural conflicts can be a drain on the energy of the people involved. Demographic changes which estimate that only $15 \%$ of new entrants into the labor force are white males, compared to $47 \%$ just twenty years ago, will command changes in the management of organizational culture and force organizational adjustments in terms of structural integration and institutional biases. Organizations now recognize the impact of diversity on performance and profitability as was predicted by the Hudson Institute's study "Workforce 2000: Work and Workers for the $21^{\text {st }}$ Century (Johnston, 1987). Diversity brings with it advantages or opportunities as well as disadvantages and challenges. 


\section{ADVANTAGES OF DIVERSITY}

There is substantial literature which argues that diversity has performance advantages over homogenous work structures (Cox, Lobel and MacLeod, 1991; Cox and Blake, 1991). First, multicultural organizations have an advantage in attracting and retaining the best talent. The capabilities of women and minorities offer a wider labor pool. Organizations that are able to attract and retain qualified minority group members and keep faith with them through fair and equitable career advancement treatments, gain competitive advantage and derive high quality human resources dividends. Second, a multicultural organization is better suited to serve a diverse external clientele in a more increasingly global market. Such organizations have a better understanding of the requirements of the legal, political, social, economic and cultural environments of foreign nations (Adler, 1991). Third, in researchoriented and hi-tech industries, the broad base of talents generated by a gender-and ethnic-diverse organization becomes a priceless advantage. "Creativity thrives on diversity" (Morgan, 1989). Fourth, multicultural organizations are found to be better at problem solving, possess better ability to extract expanded meanings, and are more likely to display multiple perspectives and interpretations in dealing with complex issues. Such organizations are less susceptible to "groupthink." Fifth, multicultural organizations tend to possess more organizational flexibility, and are better able to adapt to changes. Women, for instance, are said to have higher tolerance for ambiguity than men (Rotter \& O'Connell, 1982). A study of the U.S. Forest Service suggests advantages of a culturally diverse organization in the development and management of natural resource policies. It concluded that the creation of a diverse mix of employees was not only more reflective of the diverse public which the Forest Service serves, but also resulted in better land management decisions that were more responsive to the desires and needs of the populations served (Brown and Harris, 1993).

\section{DISADVANTAGES OF DIVERSITY}

Diversity has some drawbacks which moderate its significant advantages. In problem-solving situations, extraordinary costs in time and financial resources can negate the benefits of synergy, and can even degenerate into dysfunctional conflicts. Diversity does not fare as well under conditions of uncertainty and complexity which may lead to confusion and frustration. Diversity can make it harder to arrive at an agreement on a particular course of action, and can result in negative dynamics and cultural clashes that can create work disadvantages for women and minorities. Traditionally, cultural conflicts between majority and minority group members are usually resolved in favor of the majority groups. This, in turn, creates significant barriers to full participation by minority members in potentially conflict situations. In an analysis of 151 work groups, Tsui, Egan and O'Reilly (1992) found diversity to be associated with lower levels of psychological identification with group members which would tend to detract from overall performance and result in adverse effects on organizational measures of productivity, absenteeism and turnover. Homogenous groups have been reported to outperform culturally diverse groups especially where there are serious communication issues which make it more difficult for everybody to make optimal contributions to the group effort (Sheridan, 1994).

Higher turnover and absenteeism are special problems identified with multi-cultural organizations. Several research studies since the 1960's have found women and other minorities to be consistently higher on absenteeism and turnover than their majority-member counterparts. Turnover for Blacks has been recorded at $40 \%$ greater than for Whites (Bergmann and Krause, 1968). A Corning Glass study reported that between 1980 and 1987, turnover among women in professional jobs was double that of men and the rate for Blacks was 2.5 times greater than for Whites (Hymowitz, 1989). Schwartz (1989), and Scott and McClelan, (1990) arrived at similar findings of two-toone turnover rate for women versus men. Meisenheimer (1990) found a 58\% higher rate of absenteeism for women compared to men. In a study of twenty work units, O'Reilly, Caldwell and Barnett (1989) concluded that heterogeneity in groups was associated with lower levels of group social integration which resulted in higher individual turnover. They concluded that out-group members were more likely to leave the organization. Using a hypothetical company of 10,000 employees, Cox estimated that absentee differences attributable to multiculturalism would cost a company an average of three million dollars per year (Cox, 1993, p.25). 


\section{LESSONS FOR MANAGEMENT}

In the face of mixed findings from research, and the social and legal imperatives for organizations to accommodate multi-cultures, practicing managers have a dialectic responsibility in deciding not whether, but when and how to exploit and capitalize on the positive attributes of cultural diversity while avoiding its downsides.

The first step is to understand that one of the primary objectives of diversity is to acknowledge people's individualities. This requires organizations to transform from mono-cultural to multicultural models of operation. This takes a three-step development process (Gottfredson, 1992). First is a monolithic stage characterized by a demographically and culturally homogenous structure. This is exemplified by traditional Japanese firms that employed only Japanese males. Second is a plural representative stage where an organization, though culturally diverse in its rank and file, maintains a culturally homogenous leadership. Sub cultures and groups are then expected and encouraged to adopt the culture of the leadership. This characterizes many current American organizations. The final stage is the truly diverse model where multicultural accommodation is evident throughout the organization. Companies at this stage value diversity and encourage it through a variety of ways that include two-way learning, and mutually reinforcing adaptation, interdependence and appreciation of cultural differences. Research makes several suggestions in effective and successful management of cultural diversity. Top management support and commitment must be evident. CEO's must also be willing to submit to diversity training to appreciate organizational barriers that impede full contributions from all members. Second, diversity must be a part of an organization's planned business objective including its outreach programs, rather than a mere technical effort to fulfill affirmative action or similar legally-mandated activity. Third, there should be a mechanism to hold managers accountable for meeting diversity goals. This should be reflected in the performance evaluation process. The acid test should include how much and how fast the organization breaks the "glass ceiling" to increase the percentage of minorities and women in the higher salary echelons through career development opportunities, mentoring and meritorious executive appointments. Fifth, there must be open communication lines that allow for transmission of new ideas, grievances and feedback. Finally, organizational rituals and rites should make room for such things as religious holidays, diet preferences and dress modes that do not interfere with organizational activities. These are little things that demonstrate respect and support for cultural diversity. In addition, successful diversity management requires managers to "unlearn practices rooted in an old mind set, change the ways organizations operate, shift organizational culture, restore policies, create new structures, and redesign human resource systems"(Cox, 1993).

\section{CONCLUSION}

The challenges from an increasingly diverse workplace require a search for new ways for managing behavior. Traditional paradigms that overly focus on efficiency and profitability may not be adequate to understand the dynamics of the future multi-cultural organization. More emphasis on the current trend toward non-hierarchical, decentralized and flat organizational structures will be a positive step forward. Over and above all this is the creation of a climate that accepts and values the opportunities and challenges inherent in a diverse workforce.

\section{REFERENCES}

1. Adler, N.J. (1991). International Dimensions of Organizational Behavior, Boston: PWS-Kent Publishing Company.

2. Bergmann, B.R., Krause, W.R. (1968). Evaluating and Forecasting Progress in Racial Integration of Employment. Industrial and Labor Relations Review. 18, 399-409.

3. Blau, P.M. (1977). A Macro-sociological Theory of Social Structure. American Journal of Sociology, 83, 26-54.

4. Brown, G. and Harris, C. C. (1993). The Implications of Workforce Diversification in the U.S. Forest Service. Administration and Society, 25, 1, 85-113.

5. Copeland, L. (1988A). Making the Most OF Cultural Differences at the Workplace. Personnel, 66, 6, 5260.

6. Cox, T.H., and Blake, S. (1991). Managing Cultural Diversity: Implications for Organizational Effectiveness. The Executive, 5, 3, 45.56. 
7. Cox, T.H. (1993). Cultural Diversity in Organizations: Theory Research and Practice. San Francisco: Berrett-Koehler.

8. Cox, T.H., Lobel, S.A., and Mcleod, P.L. (1991). Effects of Ethnic Group Cultural Differences on Cooperative and Competitive Behavior on a Group Task. Academy of Management Journal, 34, 4, 827847.

9. Earley, P.C. (1993). East Meets West Meet Mid-East: Further Explorations of Collectivistic and Individualistic Work Groups. Academy of Management Journal 36, 2, 319-348.

10. Everett, M. (1990). Let an Overweight Person Call on Your Best Customers? Sales and Marketing Journal. $142,4,66-70$.

11. Firebaugh, G. and Davis, K. (1988). Trends in Anti-Black Prejudice, 1972-1984: Region and Cohorts Effects. American Journal of Sociology, 94, 2, 251-272.

12. Gottfredson, L.S. (1992). Dilemmas in Developing Diversity Programs in Jackson, Susan E. ed. (1992). Diversity in the Workplace, N.Y.: Guilford Press.

13. Hofstede, G. (1980). Culture's Consequences. Beverly Hills, Ca.: Sage Publishers.

14. Hymowitz, C. (1989). One Firm's Bids to Keep Blacks, Women. Wall Street Journal. (Feb. 16).

15. Inkeles, A. (1983). The American Character. The Center Magazine, 16, 25-39.

16. Johnson, W.B. (1987). Workforce 2000: Work and Workers for the $21^{\text {st }}$ Century. Indianapolis, IN: Hudson Institute.

17. Lester, R. \& Caudill, D. (1987). The Handicapped Worker: Seven Myths. Training and Development Journal, 41, 8, 50-51.

18. Lincoln, C.E. (1967). Color and Group Identity in the United States. Daedelaus, 1, 2, $527-541$.

19. Meisenheimer, J.R. (1990). Employee Absences in 1989: A New Look at Data from the CPS. Monthly Labor Review, (August) 28-33.

20. Morgan, G. (1989). Endangered Species: New Ideas. Business Month, 133, 4, 75-77.

21. Morrison, A.M. (1992). The New Leaders: Guidelines on Leadership Diversity in America. San Francisco: Jossey-Bass Publishers.

22. Nkomo, S.M. (1992). The Emperor Has No Clothes: Rewriting Race in Organizations. Academy of Management Review, 17, 487-513.

23. O'Reilly, C.A., Caldwell, D. F. and Barnett, W.P. (1989). Work Group Demography, Social Integration, and Turnover. Administrative Science Quarterly, 34, 1, 21-37.

24. Perkins, A.G. (1993). Diversity. Harvard Business Review. 71, $5,14$.

25. Ramakrishnan, K.R. AND Balgopal, P. R. (1995). Role of Social Institutions in a Multicultural Society. Journal of Sociology and Social Welfare, 22, 1, 11-28.

26. Romano, C. (1995). Managing Change, Diversity and Emotions. Management Review, 84, 7, 6-7.

27. Rotter, N.G. and O’Connell, A.N. (1982). The Relationships Among Sex-Role Orientation, Cognitive Complexity, and Tolerance for Ambiguity. Sex Roles, 8, 1209-1220.

28. Rubaii-Barrett, N. and Beck, A. C. (1993). Minorities in the Majority: Implications for Managing Cultural Diversity. Public Personnel Management, 22, 4, 503-521.

29. Schweltzer, N. J. and Deely, J. (1982). Interviewing the Disabled Job Applicant. Personnel Journal, (March) pp. 205-209.

30. Scott, K. D. and McClellan, E. L. (1990). Gender Differences in Absenteeism. Public Personnel Management, 19, 2, 229-253.

31. Shimp, T. A. and Sharma, S. (1987). Consumer Ethnocentrism: Construction and Validation of the CETSCALE. Journal of Marketing Research, 24, 3, 280-289.

32. Triandis, H. C., McCusker, C. and Hui, C. H. (1990). Multi-Method Probes of Individualism-Collectivism. Journal of Personality and Social Psychology, 59, 1006-1020.

33. Tsui, A. S., Egan, T. D. and O'Reilly, C. A. (1992). Being Different: Relational Demography and Organizational Attachment. Administrative Science Quarterly, 37, 4, 549-579. 